\title{
Douglas Bennett
}

\section{In conversation with Greg Wilkinson}

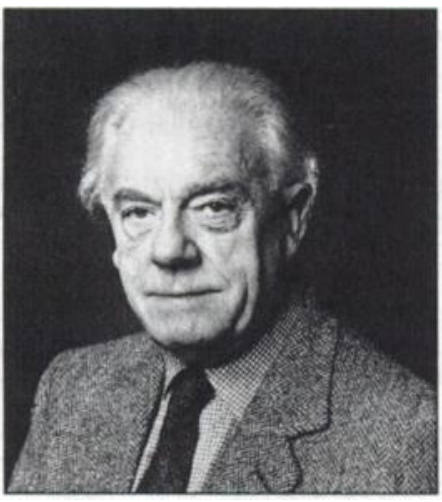

Douglas Bennett

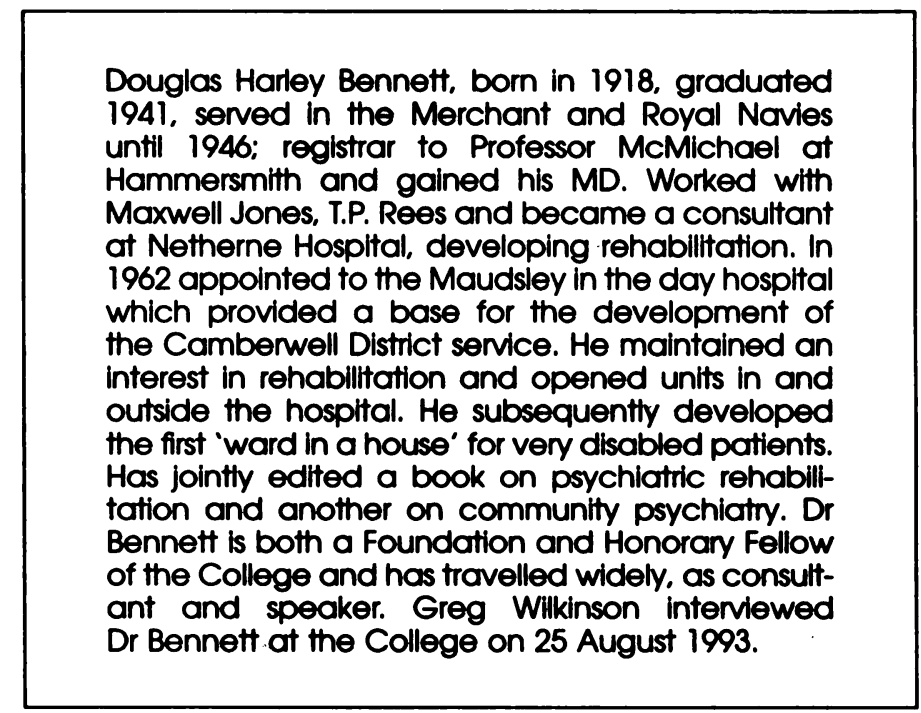

What prompted your interest in psychiatry?

I went to London for interviews at University College Hospital and St Bartholomew's Hospital, where I was accepted. We did the pre-clinical work at Charterhouse Square and then moved over to the main hospital where I suppose we had about a year or a little more before World War II broke out. During that year Jung was invited to give two lectures by E.B. Strauss who had been appointed as psychiatrist a couple of years before the war. This stimulated my interested in psychiatry. I remember Strauss remarking that "psychiatry was the other half of medicine".

Tell me about your early career.

I qualified at age 22 and did a short house job at the old London Fever Hospital in Islington. After a stint there I got a house surgeon's job at Bart's, about which I remember little. Then I did another six months at The Royal Northern. Before being appointed one had to visit all the relevant consultants up and down Harley Street. I believe that we were the first appointees who were not required to wear black jackets and striped trousers because of wartime circumstances.
I then went into the Merchant Navy and became a ship's surgeon on a Dutch merchant ship. I transferred to the Royal Navy and before I was demobbed I was posted to Barrow Gurney Hospital (then partially or wholly run by the Navy) as a medical specialist, where Surgeon Captain Curran and Surgeon Captain Critchley were the psychiatric and medical specialists.

I cannot remember how I decided that I needed to go to the Hammersmith Postgraduate Hospital but I thought I was destined for general practice and that I needed to refresh my knowiedge of general medicine after the war years. I was interviewed by Paul Wood who gave me a house physician's job on Professor McMichael's firm and as a result, my whole orientation changed. Hammersmith was an amazing experience for me. It developed my interest in a medicine based on research results, which was uncommon in 1946, and the people that I worked with were a very inspiring crowd: Sheila Sherlock, SharpeySchaefer, Bywaters and Russell Fraser. I was not particularly interested in psychiatry at this time but I found the cardiac and liver research awe-inspiring. 
I failed the MRCP and was not reconciled to this for some time although I passed the MD in Medicine. There were a number of very able people queuing up for consultant posts when the National Health Service started in 1948 and McMichael advised me to go for one of the "lesser specialities'. I had done skins with Roxburgh at Bart's and I did not fancy chest diseases, but I had been helping a psychiatrist called Beresford Davies at Fulham Hospital Observation ward and I liked the work, although the unit left much to be desired. Professor McMichael suggested the Maudsley but at Hammersmith we had always had so many 'refugees' from Aubrey Lewis that I was not prepared to risk it. I was also considerably influenced by Beresford Davies who later practised in Cambridge.

You took the plunge.

The new South West Thames Regional Board were offering training posts and I approached Dr Garmany, the regional psychiatrist. This was a lucky experience for me as Dr Garmany suggested that I start with Maxwell Jones at Belmont, go on to T.P. Rees at Warlingham Park and finish with Hilliard at the Fountain. In their different ways they were all pioneers in rehabilitation and this experience set my course in the years ahead. Maxwell Jones was the only one to give me some formal training and made me present two cases a week. Training completed in 1951; I had the DPM and I was looking for a job again.

There was no job at Belmont and I applied to Dr Freudenberg at Netherne. Again this was a lucky break for he was a charming and liberal man who was shyly formal in manner but a generous friend to me and many others. He came from a very distinguished German industrial family who owned what was in those days the biggest private enterprise in Europe, situated in Weinsberg which is near Heidelberg. His nephew still takes a philanthropic interest in psychiatry because of this connection and the Freudenberg Foundation does a lot for psychiatry in Germany.

I was appointed as an SHMO, a post now abandoned (something between a senior registrar and a consultant) and my research interest was rather exotic as I attempted to study the Body Percept and the Body Concept.

You became interested in social psychiatry.

Although he had played a part in introducing insulin coma therapy into this country, Dr Freudenberg was also interested in social treatment. In 1953 or 1954 Dr Freudenberg and I visited Querido in Amsterdam and were so impressed with the community developments there that Dr Freudenberg applied for some money to set up a community service in our catchment area. However, we were beaten in the race for this money which went to Dr Carse at Graylingwell and resulted in the Worthing Experiment. I remember being disappointed but decided instead to set up a rehabilitation service at Netherne Hospital.

In 1957 Tony May and I accompanied Dr Freudenberg to Zurich where he gave a paper (to which we had contributed) on the relative value of physical and social treatment. This work was undertaken before the introduction of phenothiazine medication. In the same year he also encouraged me to set up a resettlement unit for male and female patients, probably one of the first mixed sex psychiatric units for long-stay patients in this country.

Led by Dr Freudenberg we came to hold, what was at that time and perhaps still is, an unusual attitude to the care of long-staying patients: an attitude which I came to designate as 'upside down' psychiatry. In other words, we put all the senior consultants into the long-stay wards and left the more junior staff in charge of the acutely ill patients. This made good sense as the senior consultants were the longest staying staff with the most authority to change the conditions in the chronic wards. Dr Freudenberg was also the first psychiatrist to propose the idea of informal patients.

These attitudes, which I regard as Netherne's most important innovation, played some part in my later work at the Maudsley. Dr Freudenberg also engaged a social psychologist and a sociologist to look at what we were doing. We established a friendship with Drs John and Elaine Cumming from Canada and Dr Freudenberg also invited Morris and Charlotte Schwartz from the USA to visit. Both couples were distinguished pioneers in social psychiatry. This social outlook was later augmented by John Wing and George Brown who came to Netherne and started their study of institutionalism and schizophrenia; this had a great influence on my thinking about rehabilitation and community care.

\section{What about work?}

At that time we had little idea of what patients could do, although we had been impressed by the work of Jack Tizard and Nell O'Connor with the mentally retarded. However, I introduced some paid work in the hospital as a means of trying the patients out before discharge and was surprised and impressed to see its effects on the mental state of patients. That too started an interest in work for psychiatric patients which was to continue and influence my future practice. My time was more and more taken up with rehabilitation, which at that time was mass produced. One had a couple of hundred patients to help and so I introduced group methods, which were adapted 
from my Belmont experience, with which the staff in the resettlement unit rapidly became adept. In our work at Netherne we had to reconstruct patients' personalities and histories which had been completely lost in the passage of the years and in the very inadequate case-notes. We also took part in a study which Wing made of our results in the resettlement of patients with schizophrenia in the IRU at Waddon.

You moved to the Maudsley Hospital.

In 1962 the Maudsley Hospital was looking for someone to replace Dr Arthur Harris on the staff. While I never knew what was happening in the discussions leading up to the post being advertised, I imagine that Sir Aubrey Lewis and some members of the staff had realised that times were changing and that community psychiatry was a future trend. I was appointed to be in charge of the day hospital and had nominal charge of the out-patient department and the emergency clinic.

I had never intended an academic career and I found the work at Maudsley stressful, working not directly with patients, but instead supervising the work of registrars. I felt it was like eating a meal with a very long knife and fork: one felt so far removed from the patient. Nevertheless, I enjoyed the high standards, the intelligent registrars, the smaller case-load, and the ability to look at and talk in detail about what one was doing. I also enjoyed the team work with the unusually good nurses, excellent social workers (including Tessa Jowell, now Peckham's MP) and some outstanding psychologists many of whom developed a helpful interest and skill in rehabilitation. They included Geoff Shepherd, Fraser Watts, Isobel Morris, Philippa Garety among others. This gave a great impetus to our work with rehabilitation. Some of the interesting people I worked with at the Maudsley were German students who have become liberal and reforming professors in various parts of Germany; they include Professor Kunze, Professor Bauer and Professor Finzen among others.

You became interested in resettlement.

My initial efforts were an extension of my experience at Netherne Hospital so I persuaded those with influence in the hospital to let me develop a vocational resettlement unit (VRU) after the day hospital had been moved from Denmark Hill to Windsor Walk in 1967. At that time I had not appreciated the difference between the rehabilitation of patients who had spent long years in hospital and those who were no less disabled but were more recent cases; nor the difference between rehabilitation in a ward and in a day hospital. The first was the difference between 'early' and 'late' rehabilitation, and the second was the difference between that of patients under the control of an institution and those who were not. I soon appreciated this when John and Lorna Wing and the Medical Research Council research team studied our practice and showed that the results were not better, and some even worse, than those I had obtained at Netherne.

When developing the VRU I obtained the advice of a consultant from the Department of Employment. He advised that we engage two toolmakers to run the workshop and they did such splendid work that I saw the possibility of starting a sheltered workshop to supplement the services provided by our local Remploy factory. I raised a certain amount of money and we established the Camberwell Rehabilitation Association (CRA) and secured a small factory in Bassano Street, and the toolmakers, who were still working in the VRU, ran it making use of their industrial 'know how'. Later we moved the factory to larger premises in Oglander Road and closed the VRU, moving the people from that unit to share the factory with the sheltered workers.

How did this influence your view of the hospltal?

I was also influenced by the fact that for about five years I had no beds at the Maudsley or anywhere else: that profoundly changed my thinking about hospital treatment. Other changes were taking place; John Wing introduced the Camberwell Register and subsequently we introduced the idea of a Camberwell service and eventually ceased admitting patients to Cane Hill. In other words, Dr Tony Isaacs and I ran down our beds in the mental hospital, not by discharging ex-patients to the community, but by admitting all new patients, to St Francis and the Bethlem and Maudsley instead of Cane Hill.

This was a profound change and depended on not only knowing what was happening to Camberwell patients from the Register but on the co-operation of a few colleagues. I do not think that by any stretch of the imagination one could consider that the establishment of a Camberwell Service was, or is, a popular idea at the Maudsley and without help from a few committed people it would have been impossible to carry it out. This meant that my main effort at the Maudsley was with chronic patients except in my out-patient clinic and at times in the day hospital but the Camberwell service in its various forms became my dominant interest.

You maintained other interests.

At this time I also did a certain amount of work with the World Health Organization in Copenhagen on logging the psychiatric services in Europe and some years later went on to Trieste for WHO to look at Dr Basaglia's service 
on which I wrote a report and some articles. But the chronic patient was my main concern and I felt that it was important to get the chronic patients into the Maudsley. It remained with me, since my experience at Netherne, that psychiatry was upside-down with the least 111 and least disabled patients being treated by the most able and qualified staff. I believed that it would make a great difference if we could change this and bring these unfortunate people to the attention of the best therapists.

I do not believe that I was successful in changing the outlook of many psychiatrists (with some notable exceptions including Dr Jim Birley) but we did have some success in moving chronic patients from Cane Hill and St Francis Hospitals to the Joint Hospitals.

1967 saw the beginning of my collaboration with Dr Tony Isaacs and the joint co-operation of the St Francis and Cane Hill services. Tony and I were both given beds at St Francis Hospital. I was also given beds at Cane Hill and Tony was given beds at the Joint Hospital. By being on duty on alternate days we were able to police admissions which were still disposed of on the lines set down by Mapother; the 'objecting and objectionable' to St Francis the 'accepting and the acceptable' to the Joint Hospital and the chronic long-stay patients to Cane Hill. We often had to redirect patients who had been wrongly admitted to Cane Hill back to Camberwell.

Jim Birley worked with me in the Emergency Clinic, later in the Day Hospital, while subsequently he became Dean of the Institute. In those days we used to have regular meetings with $\mathrm{Dr}$ Epsom, the MOH in Camberwell who later became Medical Officer of Health in Southwark after the new borough had been established. We were urging the establishment of a hostel or other accommodation for local patients with psychiatric disabilities when they were discharged from hospital. However, I discovered that the provision of accommodation for ex-psychiatric patients had no place in Southwark's plans so I asked Jim if he would see what he could arrange and he set up Windsor Walk Housing Association in 1970. It is not too usual to find a housing association being run by the President of the College.

It may not be appreciated how much my friends Jim and Tony supported me - Tony as Chairman of the Medical Committee, Jim as Dean of the Institute, nor how much we all depended on the expertise of John Wing as Professor of Social Psychiatry.

You are known for your work on day care and a family approach.

In 1969 some money became available to Professor Wing and it was decided to build a new unit for Camberwell patients. I was very interested in the development of day hospitals and was preoccupied with the realisation that day hospitals were not a substitute for in-patient care but an alternative for some patients. I thought that a day hospital with beds might solve the problem of continuity of care for these patients and briefed the architects accordingly. Frances Aitken was Maudsley planning officer at the time and together with the architect we visited some establishments that I had seen previously, or knew of, in the USA.

In the meantime, the clinical work continued in the day hospital and was greatly enhanced by the interest and influence of $\mathrm{Dr}$ Robin Skynner. He came to the day hospital for an hour each week and held a group which was attended by all the day hospital staff. The staff of the day hospital was diverse in their skills, interests, training and duration of their stay. Like the patients, they brought ideologies, preconceptions and prejudices about hospitals, patients and illness, as well as ideas about their own role and that of other staff members. They all remained under the direction of their departmental heads, so that the psychiatrist was not their manager. He could not hire or fire them, yet he had to help them find some common framework, some common ground, some common language and some common attitude to the unit and to each other. It seemed clear that the traditional hierarchical method of consultant management was not a satisfactory answer when one is not dealing with routine matters such as appendicectomies, but with 'one off psychiatric situations where a person's behavlour and relationships were not routinely predictable. We needed a system that would allow any staff member, however junior or senior, from any discipline, to take charge of any situation and to be confident that he or she knew what was happening or if not, could call on any other staff member and could be confident that they would receive information or support. Robin Skynner's weekly groups in which he avoided personal interpretations but examined the interactions within the staff group helped to resolve some of these problems.

Another important development with which Robin Skynner helped us was the introduction of a family approach. His main contribution was in introducing the staff to the ideas and methods of family treatment. This was extremely important in a day hospital where the patients each week spent 40 hours or less with the staff and 120 hours in their family homes. Many members of staff from different disciplines became very competent in this approach, and attended Dr Syknner's groups for supervision of their work. 
You developed the concept of a district services centre.

The District Services Centre at the Maudsley Hospital was eventually constructed and opened in 1981. In its design, my idea was to combine day treatment, in-patient care and possibly outpatient interviews in one place so that continuity of the staff-patient relationship could be maintained. In short it was to be a day hospital with beds. There were what are known today as 'fault lines' and its operation and structure should have been modified, but this was never done and now it has been outmoded, perhaps, by changes in national policy and by an alteration in the Maudsley's future role. But it did play a useful part in the closure of Cane Hill and St Francis Hospitals and in bringing the chronic patient into the Maudsley orbit.

Tell me about the hospital hostel you became involved with.

One other scheme which I am proud to have been involved in was 111 Denmark Hill, a ward-in-ahouse for patients needing a longer hospital stay than is usual today. Its operation owes most to Herman Afele and Sue Lewis who were the senior nurses and to Isobel Morris and Philippa Garety, the psychologists. There have always been psychologists in charge of the day to day working of the unit, although its operation was my responsibility. Together we devised a plan with a view to providing for the non-institutional operation of what is essentially an institution. The psychologists looked back to the work of King, Raynes and Tizard and adopted their principles for countering institutionalism. The second step was to institute rehabilitation programmes; having discussed the patient's problems with the staff and having agreed an order of priority, members of the staff sought to deal with only two patient problems at a time and to make charts on which the patient's compliance with the programme was recorded four times a day. The third step was to recognise that the staff were the only form of therapy and that this unrewarding work put them under great strain in terms of their relationships with other staff and patients. We took account of their needs in a weekly meeting taken by a psychotherapist from outside the unit who acted as a referee and elucidated some of the conscious and unconscious causes of our discontents. The psychologists also prepared graphs to show whether the daily charts were or were not demonstrating any progress in our rehabilitation programme. We never really established why the programme was so successful; was it the diffusion of conflict or the feedback of results or was it the staff involvement in all decisions or was it a combination of all three?

How do you see the future for rehabllitation psychiatry?

Rehabilitation has changed with the closure of the 'asylum' hospitals, but it will still be needed in the community, because in future psychiatrists will no longer be rehabilitating those longstay patients who tended to adapt in a passive fashion. They will have to help a younger group of disturbed psychotic patients who have not accepted their disability, nurture unrealistic ambitions, may take addictive drugs and will not have had a long stay in hospital. This is not all; we have to realise that the disabilities of the mentally ill lie in their difficulty in playing roles in a social environment. When the physically handicapped cannot cope with the physical environment we modify it with ramps, lifts, wheelchairs and other devices. Changing the disabled psychiatric patient's social environment is going to be a much more challenging task. Roles depend on relationships with other people; they are not created out of skills training or thin air. It will not be easy to change the attitudes and behaviour of those around the psychiatrically disabled person, even within his or her own family. For the rest we shall have to provide some of the features which the hospital provided. These include social support, social structure (having to be somewhere to do something with somebody at a certain time), the immediacy and continuity of available medical and caring services and, of course, somewhere to live and financial resources. Psychiatrists will not only have to work in a multidisciplinary, but also in a multi-agency fashion. It will not be easy. 